\title{
Influence of Tumbling Bodies on Surface Roughness and Geometric Deviations by Additive SLS technology
}

\author{
Jiří Lichovník, Ondřej Mizera, Marek Sadílek, Lenka Čepová, Jan Zelinka, Robert Čep \\ Faculty of Mechanical Engineering, VŠB - Technical University of Ostrava. 17.Listopadu 2172/15, 70800 Ostrava \\ - Poruba. Czech Republic. E-mail: jiri.lichovnik@vsb.cz, ondrej.mizera@vsb.cz, marek.sadilek@vsb.cz, lenka.ce- \\ pova@vsb.cz,jan.zelinka@vsb.cz, robert.cep@vsb.cz
}

This research focusing on influencing the surface structure and its geometric deviations from the CAD model after various tumbling of bodies at constant parameters of the tumbling machine. The purpose of determining the actual effect on the resulting surface before and after the tumbling process, which tumbling body causes the selection of a larger grain or compaction of the surface layer. The research outputs are thermographic maps and geometric deviations measured using CAD models. The experimental line was at VŠB - TU Ostrava, with the help of the PROTOLAB 3D printing center, there was an experimental sample in your game. Measurement of access in the metrology laboratory on CMM Wenzel LH 65 X3Premium and optical heads Shapetracer II.

Keywords: 3D CMM, Optical scanning, Geometric deviations, Aditive Technology, Method S

\section{Introduction}

In the last decade, 3D printing has become a very popular and affordable means for realizing designs from the CAD software into a physical state [1].

$3 \mathrm{D}$ printers that allow you to print from plastic can vary in the technology used when making the parts. The difference in the used printing technology often mean a different printer design, but also different applications of the printed parts. The printed parts may be different in mechanical properties, accuracy, size, consistency or even appearance. [8] [10]

$3 \mathrm{D}$ printing may seem as a fast way to produce the designed parts. However, from an industrial point of view, especially in mass production it is much slower than injection moulding. The advantage of $3 \mathrm{D}$ printing is not the speed of production or low price, but the ability to produce prototypes, or in one-off production it is suitable for even very complex parts that cannot be produced by other methods. This applies for the parts whether they are only design parts or in the case where topology optimization is applied to stress-based structural design problems in parts.

The most frequent requirements for printed parts are optimal mechanical properties combined with the accuracy of functional surfaces. In order to determine whether a particular part is manufactured accurately, it is necessary to use both conventional measuring instruments, custom gauges and non-traditional measuring devices, that is mainly because of the complexity of the manufactured parts. A comprehensive evaluation of the surface topography of a shin guard is given by using a tumbling machine, which adjusts the shin guard's surface to appear visually smoother using selected tumbling bodies. Adjusting may mean a refinement of the surface layer, strengthening (compaction) of the surface layer and also the least suitable for us a change of geometric dimensions. In the process there is a rounding of the edges, a change in length, a change in angle, etc. From a process point of view, the goal of the tumbling bodies is: smoothing, polishing, deburring, rounding of the edges and precise final adjustment.

The surface topography is analysed from a qualitative point of view to evaluate the functionality and assembly of the surface [3]. Requirements for the final surface topography are most often determined for the following reasons: low noise, adhesion, anti-vibration, frictional heat transfer, abrasion resistance, surface appearance, etc [19]. It is not always necessary to produce a surface as gloss, if not needed. Each process operation makes production more expensive. It is always necessary to consult with the customer or with the production technologist. [6]

\section{Experiment}

Selective laser sintering (SLS) is a modern manufacturing technology that was created in the 1980s at the University of Texas in Austin's Department of Mechanical Engineering [2]. SLS has become one of the most advanced and promising production methods in the world [7] that is used today thanks to the invention of Carl Deckard [4] [18].

\section{Print Creation}

The SLS method was chosen because of the problematic and more complex structural elements used in the designed experiment. In this case, the removal 
of support is eliminated, as the surrounding of the tray serves as support for the printed part. The design of the printing process is assessed from the design point of view and the orientation of the model in the build chamber of the 3D printer. Today's possibilities allow printing surfaces at any angle without the use of supports, there is a direct dependence of a certain slope with deteriorated surface quality.

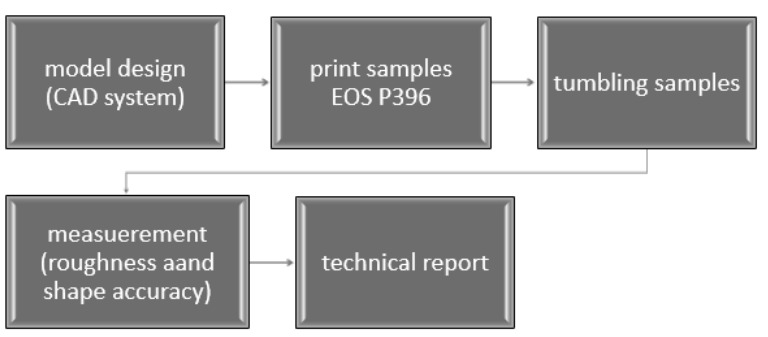

Fig. 1 Proces flow diagram

For the selected samples, we chose the EOS P396 printer, which prints using the SLS method. The samples were printed in a layer of 120 micrometres and in balance mode, see Figure 3. When assessing the shape of the models, the samples were printed in a vertical position in the build chamber, due to their specifications (raster designs and inscriptions). If a different orientation is chosen in the build chamber, eg. horizontal, certain deformations and higher geometric deviations from the original CAD model could occur. Incorrect selection of the orientation of the printed model in the build chamber further deteriorates the integrity of the surface of the printed part and prolongs the processing times for surface layer modifications [17].

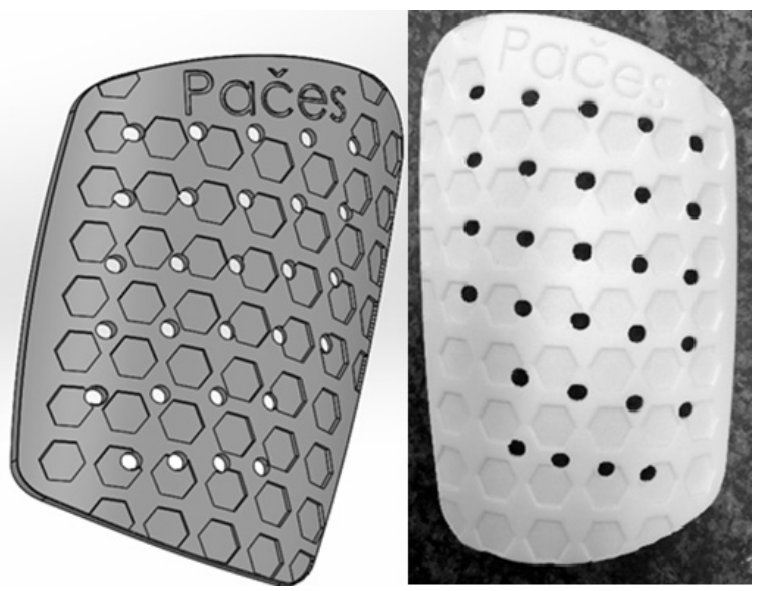

Fig. 2 Protector 3D model is on left size and next size is models printed by SLS technology

The material for the samples used was the PA 12 (Polyamide 12), which guarantees excellent mechanical and thermal properties and resistance to various chemicals. This material has a balanced profile of given properties (strength, stiffness). In addition, this material is a strong alternative to plastics, which have proved their worth in plastic injection molding, since we wanted to replace the molding or injection molding of protectors (large-scale production) by 3D printing according to a precise model, i.e. the human shin.

Tab. 1Material properties PA12

\begin{tabular}{|c|c|}
\hline \multicolumn{2}{|l|}{ Typical mechanical properties } \\
\hline Train module & $\begin{array}{l}1650 \\
\mathrm{MPa}\end{array}$ \\
\hline Tensile strength & $48 \mathrm{MPa}$ \\
\hline Elongation at break & $18 \%$ \\
\hline \multicolumn{2}{|l|}{ Thermal properties } \\
\hline Melting temperature $\left(20^{\circ} / \mathrm{min}\right)$ & $176^{\circ} \mathrm{C}$ \\
\hline $\begin{array}{l}\text { Dimensional stability temperature }(1.80 \\
\mathrm{MPa})\end{array}$ & $70^{\circ} \mathrm{C}$ \\
\hline $\begin{array}{l}\text { Dimensional stability temperature }(0.65 \\
\mathrm{MPa})\end{array}$ & $154^{\circ} \mathrm{C}$ \\
\hline
\end{tabular}

elve

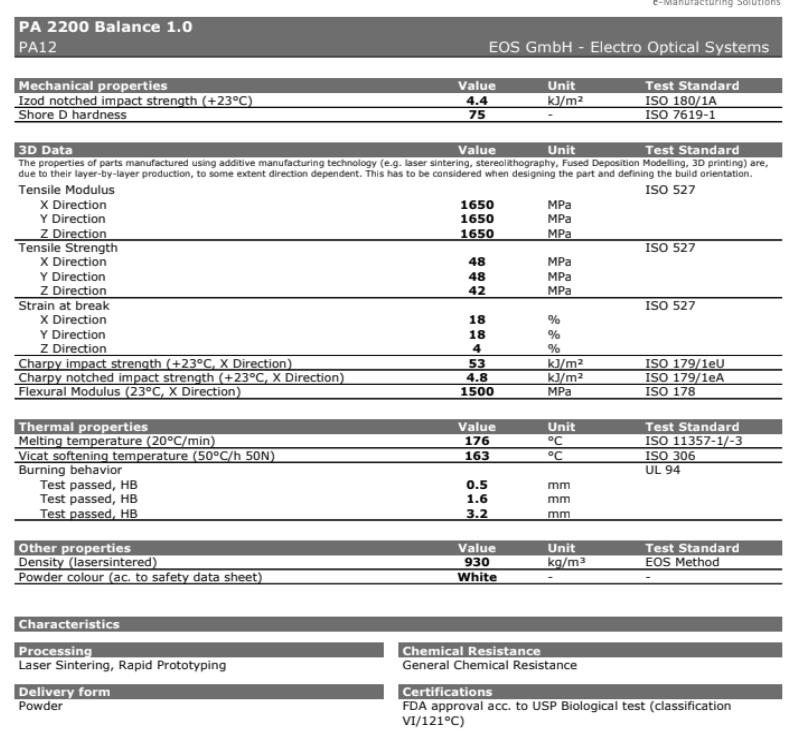

Fig. 3 Samples Printing Parameters

After printing, the parts the tumbling device was used to soften the surface layer, remove imperfections after printing, round the edges, and smooth as much as possible and prepare the surface for subsequent surface treatment by painting.

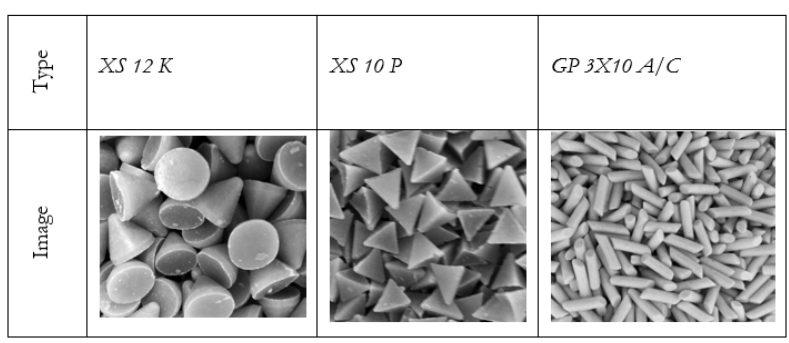

Fig. 4 Bodies used for tumbling

To smooth and eliminate imperfections after printing, three different types of plastic tumbling bodies 
from Walther Trowal, were used. These tumbling bodies are adapted for tumbling of plastics. Uniform conditions were set for tumbling parts of the selected tumbling bodies, the tumbling time was set to $25 \mathrm{~min}$ and speed of $300 \mathrm{rpm}$. The previous conditions were chosen so that after pulling the samples out of the tumbling device, the parts would seem sufficiently smooth visually and by touch.

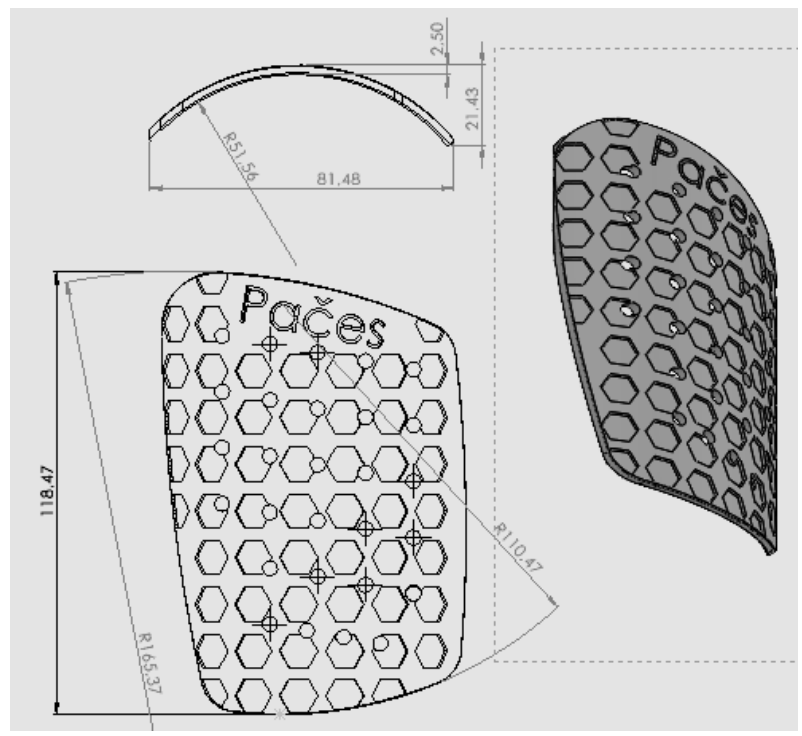

Fig. 5 Protector model

\section{Surface Roughness Measurement}

Roughness measurement was performed on an Alicona InfiniteFocus device, which is used to check the microstructure and surface topography. The device is contactless and it is based on an optical method by focusing the image at a local point. The device cap- tures the topography of the surface, including integrated shape measurement, both $2 \mathrm{D}$ (parameter $\mathrm{R}$ ) and $3 \mathrm{D}$ (parameter $\mathrm{S}$ ). The output of the measurement is a clear and illustrative graphic processing 3D surface roughness parameter $\mathrm{Sa}$ - arithmetical mean height of a surface and $\mathrm{Sz}$ - parameter is defined as the sum of the largest peak height value and the largest pit depth value within the definition area.

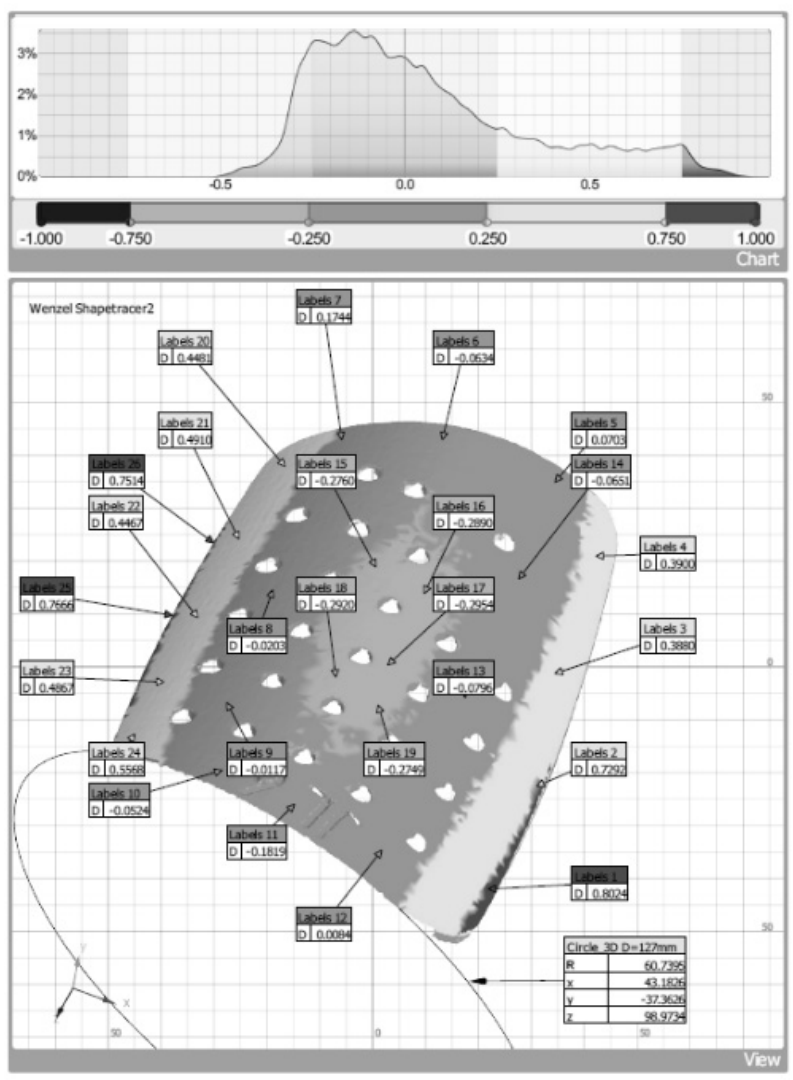

Fig. 6 Without tumbling, shape deviation evaluation protocol

Tab 2 Surface Roughness

\begin{tabular}{|l|l|l|l|l|l|l|l|}
\hline Num. & Types & \multicolumn{3}{l|}{ Sa $[\mu \mathrm{m}]$} & \multicolumn{3}{l|}{ Sz $[\mu \mathrm{m}]$} \\
\hline 1. & No Tumbling & 22.33 & 17.95 & 16.39 & 119.93 & 122.39 & 108.33 \\
\hline 2. & XS 12 K & 6.55 & 6.59 & 5.08 & 133.86 & 124.46 & 86.49 \\
\hline 3. & XS 10 P & 6.58 & 4.86 & 4.86 & 104.97 & 126.67 & 126.12 \\
\hline 4. & GP 3X10 A/C & 15.07 & 13.09 & 12.42 & 147.25 & 138.54 & 147.25 \\
\hline
\end{tabular}

Four samples were used to measure roughness, where each sample was treated with a different type of tumbling body. All tumbling processes took place under constant conditions and are therefore expressed as constants and aspects that do not affect the measurement. Every component was measured at 3 locations from which the arithmetic value was expressed. Eavery site was measured 10 times, the extreme values of the analysis were retained.

Tumblers type GP 3X10 A / C have the worst results in the analysis of surface roughness $\mathrm{Rz}$. This surface roughness is higher than before the surface treatment by the tumbling method. Therefore, in terms of surface roughness, I do not recommend the use of a tumbling body type GP 3X10 A / C to smooth the surface. 


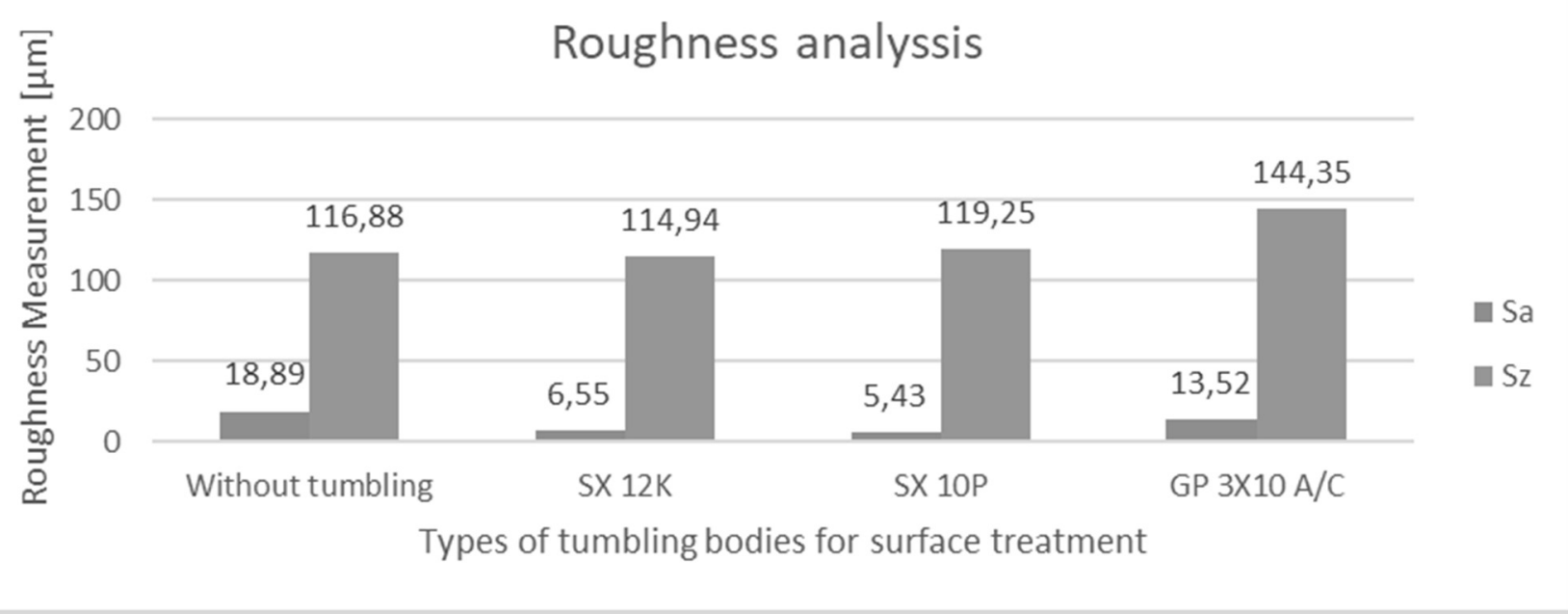

Fig. 6 Roughness Analysis

4 Measurement of geometric deviations of the shape

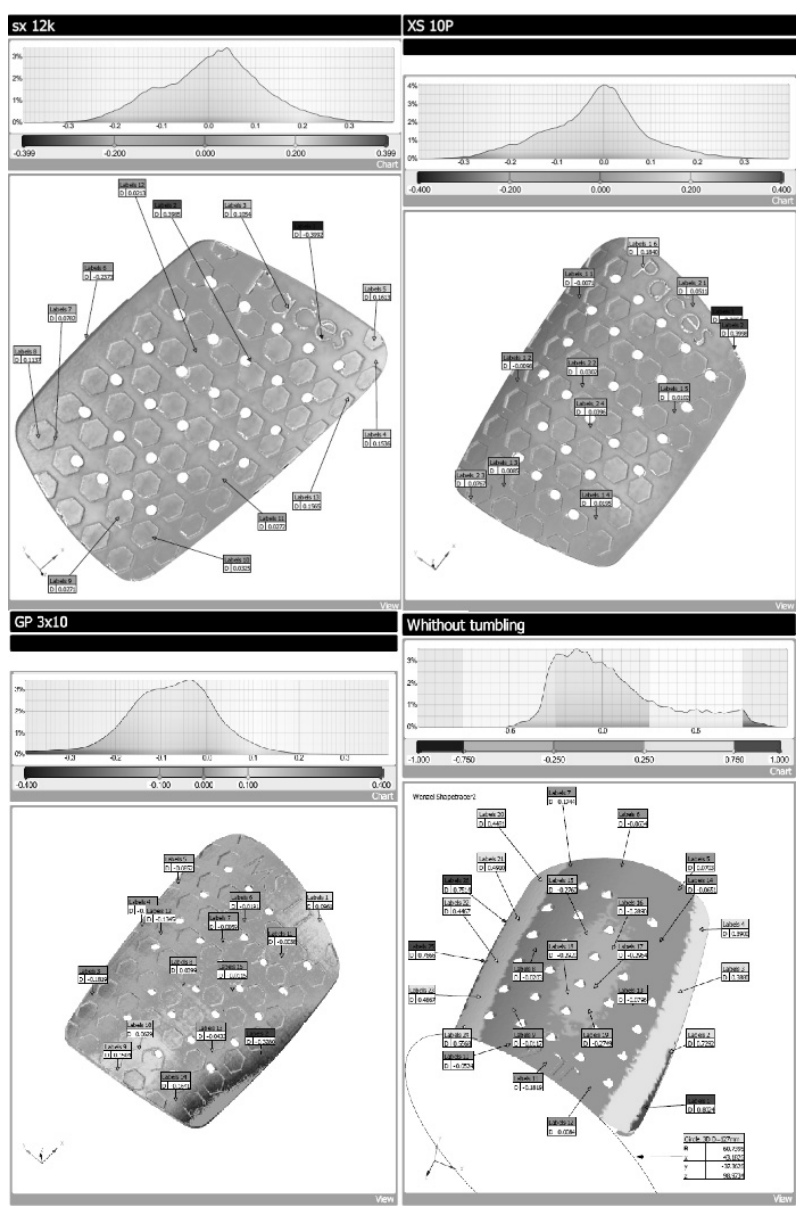

Fig. 7 Thermographic evaluations of geometric deviation of measured samples

The measurement was performed on a 3D coordinate measuring machine Wenzel LH 65 X3Premium, using an optical head Sheapetracker II. All measurements were performed with a constant scanning of a set of points. The Best Fit method was used to fit the set of points to the CAD models, the entire outer surface was scanned to evaluate the geometric deviation from the CAD model. The individual effects of tumbling bodies on the surface geometry were investigated. A thermographic map of the distance of deviations from the nominal shape was used for a clear evaluation.

\section{Conclusions}

Our result was a comparison of the CAD model from the printed samples. The roughness parameters and shape deviation from the CAD model were evaluated. Shape accuracy is directly related to surface quality. At the same time, the sample without tumbling had the largest shape deviations, where the variance of the shape deviation is $1.097 \mathrm{~mm}$, and the difference in angle $+2^{\circ} 67^{\circ} 12$ "compared to the CAD model.

The best result is the sample SX10P, which had the smallest roughness parameter $\mathrm{Ra}$ and at the same time the smallest variance of the shape deviation after filtering out the imperfections of the triangulation of the continuity of the set of points to the value of 0.398 $\mathrm{mm}$. This sample was most similar to the CAD model.

\section{Acknowledgement}

Article has been done in connection with projects from the means of state budget of the Czech Republic and by project Students Grant Competition "SP2020/60 Specific Research of Innovative Manufacturing Technologies" financed by the Ministry of Education, Youth and Sports and Faculty of Mechanical Engineering VŠB-TUO.

\section{References}

[1] ABC3D [online]. 2014 [cit. 2020-05-05]. Available from: https://www.abc3d.cz/o-3d-tisku-nepreblednete/118-k-cemu-je-dobry-3d-tisk 
[2] SLS (Selective Laser Sintering). In: COTU [online]. Praha [cit. 2020-05-05]. Available from: https:// wnw.cotu.cz/blog/126/sls-selective-laser-sintering

[3] BAKSA, T., FARSKY, J., HRONEK, O., ZETEK, M. (2019). Surface Quality after Grinding VACO 180 Tool Steel using Different Cutting Conditions. Manufacturing Technology, Vol. 19, No. 2, p. 179-183. ISSN 1213-2489. DOI: $\quad$ 10.21062/ujep/266.2019/a/12132489/MT/19/2/179.

[4] Introduction to SLS 3D printing. 3Dhubs [online]. USA [cit. 2020-05-05]. Available from: bttps:// www.3dbubs.com/ knowledge-base/introduction-sls-3d-printing/

[5] Design and development of a lightweight SLS 3D printer with a controlled heating mechanism: Part A. International Journal of Ligbtweight Materials and Manufacture. 2019, 2019(4), 5. DOI: https://doi.org/10.1016/j.ijlmm.2019.01.005.

[6] Tumbling as a universal method for surface treatment. MM Industrial Spectrum. 2002, 2002(5), 1.

[7] E. MIKOLAJEWSKA, M. MACKO, L. ZIAR NECKI, S. STANCZAK, P. KAWALEC, D. MIKOLAJEWSKI (2014). 3D Printing Technologies in Rehabilitation Engineering, J. Health Sci., 4 (12) (2014), pp. 75-83

[8] Y. XIAO, J. YANG, Q. FENG, K. HUANG, H. ZHOU, J. HU, S. DONG (2018). Three-dimensional graphene-based materials by direct ink writing method for lightweight Application Int. J. Lightweight Mater. Manuf., 2 (1) (2018), pp. 96-101

[9] URBÁNEK, A. (2008). Inspection of components using reverse engineering methods. Brno, 2008. VUT Faculty of Mechanical Engineering.

[10] DANA, M., ZETKOVA, I., HANZL, P. (2019). The Influence of a Ceramic Recoater Blade on 3D Printing using Direct Metal Laser Sintering. Manufacturing Technology, Vol. 19, No. 1, p. 23-28. ISSN 1213-2489. DOI: 10.21062/ujep/239.2019/a/12132489/MT/19/1/23.

[11] TONG, Q., XUE, K., WANG, T., YAO, S. Laser sintering and invalidating composite scan for improving tensile strength and accuracy of
SLS Parts. (2020) Journal of Manufacturing Processes, 56, pp. 1-11.

[12] NICOSIA, ALESSIO, COSTANZA DI STEFANO, VINCENZO PALMERI, VINCENZO PAMPALONE A VITO FERRO. (2016). Flow resistance of overland flow on a smooth bed under simulated rainfall. CATENA. 2020(VOLUME 187). DOI: org/10.1016/j.catena.2019.104351.

[13] HAJNYŠ, J., PAGÁČ, M., MĚSíČEK, J., PETRŮ, J., ŠPALEK, F. (2020) Research of 316L Metallic Powder for use in SLM 3D Printing. Advances in Materials Science, Vol. 20, Issue 1, p. 5-15. ISSN 2083-4799

[14] HAJNYS, J., PAGÁČ, M., MĚSíČEK, J., PETRU, J., KRÓL, M. (2020). Influence of Scanning Strategy Parameters on Residual Stress in the SLM Process According to the Bridge Curvature Method for AISI 316L Stainless Steel. Materials 13, no. 7: 1659.

[15] MESICEK, J., PETRU, J., ZLAMAL, T. (2019). The use of technology local heating by laser for turning of difficult to machine materials, Advances in Manufacturing Engineering and Materials - 2019 Proceedings of the International Conference on Manufacturing Engineering and Materials, 2019, pp. 290-298, ISBN 978-3-319-05203-8, DOI 10.1007/978-3-319-99353-9_31.

[16] JANCAR, L., PAGAC, M., MESICEK, J., STEFEK, P. (2020).) Design Procedure of a Topologically Optimized Scooter Frame Part. Symmetry 2020, 12, 755.

[17] SLS 3D Printer Buyer's Guide: What is SLS 3D Printing? ALL3DP [online]. [cit. 2020-08-12]. Available from: bttps://all3dp.com/1/best-sls-3dprinter-desktop-industrial/

[18] JJ BEAMAN, JW BARLOW, DL BOURELL , RH CRAWFORD , HL MARCUS, KP MCALEA (1997). Solid Freeform Fabrication: New Direction in Manufacturing, sv. 2061, Kluwer Academic Publishers, No well, MA ( 1997 ), s. 25 - 4

[19] STANCEKOVA, D., SAJGALIK, M., MRAZIK, J., RUDAWSKA, A., JANOTA, M. (2018). Analysis of Integrity of Surface of Hardened Chromium-Nickel Steel after Finishing Grinding. Manufacturing Technology, Vol. 18, No. 5, p. 833-838. ISSN 1213-2489. DOI: DOI: 10.21062/ujep/186.2018/a/1213 $-2489 / \mathrm{MT} / 18 / 5 / 833$. 